\title{
Salvatore Gaspa. "State theology and royal ideology of the Neo-Assyrian Empire as a structuring model for the Achaemenid imperial religion"
}

\section{Astrid Nunn}

\author{
(2) OpenEdition \\ Journals \\ Édition électronique \\ URL : http://journals.openedition.org/abstractairanica/49988 \\ DOI : 10.4000/abstractairanica.49988 \\ ISBN : 1961-960X \\ ISSN : 1961-960X \\ Éditeur : \\ CNRS (UMR 7528 Mondes iraniens et indiens), Éditions de l'IFRI
}

\section{Référence électronique}

Astrid Nunn, « Salvatore Gaspa. "State theology and royal ideology of the Neo-Assyrian Empire as a structuring model for the Achaemenid imperial religion" », Abstracta Iranica [En ligne], Volume 40-41 I 2019, document 73, mis en ligne le 30 octobre 2019, consulté le 17 avril 2021. URL : http://

journals.openedition.org/abstractairanica/49988; DOI : https://doi.org/10.4000/abstractairanica. 49988

Ce document a été généré automatiquement le 17 avril 2021

Tous droits réservés 


\title{
Salvatore Gaspa. "State theology and royal ideology of the Neo- Assyrian Empire as a structuring model for the Achaemenid imperial religion"
}

\author{
Astrid Nunn
}

\section{RÉFÉRENCE}

Salvatore Gaspa. "State theology and royal ideology of the Neo-Assyrian Empire as a structuring model for the Achaemenid imperial religion" in Wouter F.M. Henkelman, Céline Redard (eds.). Persian Religion in the Achaemenid Period. (Classica et Orientalia, vol. 16.), Harrassowitz Verlag, Wiesbaden, 2017, p. 125-184

1 Il est bien connu - et visible - que les rois achéménides ont repris un nombre significatif d'éléments assyriens. L'A. a pour but d'élucider la chronologie des adoptions, qui bien évidemment est le résultat de contacts et d'affinités culturelles.

2 L'A. débute par les contacts, en général guerriers, entre les Assyriens et les Mèdes avec les Elamites. Les sources utilisées sont surtout textuelles, mais aussi archéologiques. Il traite ensuite du concept de roi en Assyrie et en Perse achéménide et conclut que la relation exclusive entre dieu et roi est commune. Les deux cultures partagent en outre la même conception d'un dieu suprême - Ahuramazda en Perse - et d'une connotation religieuse du mandat royal permettant de régner sur le monde. La tradition assyrienne a définitivement joué le rôle d'un "modèle structurant» dans la formation de la perception achéménide impériale. 


\section{AUTEURS}

\section{ASTRID NUNN}

Université de Munich 